\title{
How Differently Does Oil Price Influence BRICS Stock Markets?
}

\author{
Jamal Bouoiyour \\ CATT, University of Pau, Pau, France \\ Refk Selmi \\ Tunis Business School, Manouba, Tunisia
}

\begin{abstract}
This article explores the strength and extent of causal relationship between BRICS (Brazil, Russia, India, China and South Africa) stock returns and real oil price using frequency domain approach of Breitung and Candelon (2006). This technique offers an appropriate alternative tool by investigating the causality in frequency domain, while standard causality tests focus only on the time domain. Using 1998-2015 quarterly data, we show that the impact of oil price on stock returns is not uniform across the investigated countries. Even though the slowly (quickly) fluctuating components of oil price exert a significant influence on real stock returns in Brazil and Russia (India and South Africa), medium and long term hidden factors were found as potential contributors of Chinese share market. The oil dependence profile, the distribution of market share between companies, the financial system efficiency and the effectiveness of regulation in securities markets have been offered to explain the heterogeneous responses of BRICS equities.
\end{abstract}

JEL Classifications: G12, O57, Q43

Keywords: Oil Price, Stock Returns, BRICS, Frequency Domain Causality

\footnotetext{
* Corresponding Author: Refk Selmi; Tunis Business School, Campus Universitaire de la Manouba, 2010, Tunisia; Tel: +21671600 615, Fax: +216 71601 311, E-mail: s.refk@yahoo.fr.

Co-author: Jamal Bouoiyour; CATT, University of Pau, Avenue du Doyen Poplawski, 64000 Pau, France; Tel: +33 (0) 5594080 01, Fax:+33 (0) 5594080 10, E-mail: jamal.bouoiyour@univ-pau.fr.
} 


\section{Introduction}

The emerging economies, collectively known as Brazil, Russia, India, China, and South Africa (BRICS), have grown rapidly and are becoming more integrated with the most developed economies, especially in terms of trade and investment. These countries constitute more than a quarter of the world's land area. As of 2015, they represent more than 3 billion people ( $42 \%$ of the world's population) and approximately $15 \%$ of the global Gross Domestic Product (GDP). In addition, these economies are expected to consume a substantial share of the world's oil and are expected to constitute more than $45 \%$ of the world's stock market capitalization by 2030 (the year when China is expected to overtake the United States). The BRICS stock markets seem to be a promising area for international portfolio diversification.

These five giants differ considerably in terms of oil characteristics. Brazil is the 12th largest oil producer in the world with more than 50 oil companies engaged in oil exploration, and it has been a net exporter since 2011. However, the country remains a net importer of some light oil from the Middle East. Meanwhile, Russia is one of the major net exporters of oil, ranked 2nd in the world after Saudi Arabia. It has the largest deposits of natural gas, with more than $26 \%$ of the world's natural gas reserves. Naturally, the Russian stock exchange is dominated by oil and gas companies, representing approximately $60 \%$ of the total market capitalization. China and India are highly industrialized and rely considerably on oil as a source of energy. More specifically, India is the world's 6th largest consumer of oil, and Indian oil production constitutes $1.1 \%$ of the world's oil production and approximately $3 \%$ of the world's oil consumption. In addition, gas and oil companies represent only $1.4 \%$ of the Indian stock market. The petroleum industry in China has been intensely influenced by the country's growing population and its lack of national oil reserves. Due to the growing population of more than 1.3 billion people, China relies heavily on other states for resources such as oil. The Chinese stock market appears to be sensitive to the energy sector since oil and basic materials amount to roughly $16 \%$ of the Shanghai Composite Index. Finally, with regard to South Africa, oil and gas companies represent approximately $4 \%$ of the total stock market capitalization. Oil in this country is largely used for electric power generation, industrial production, agricultural fertilizers, and machinery. In fact, $61.4 \%$ of oil is consumed by the transportation sector (EIA 2011).

A question widely motivated from the existing literature is whether the differences in 
the responses of stock to oil price changes depend on the fact that they are oil importer or exporter (Cologne and Manera (2008), Park and Ratti (2008), Kilia and Park (2009), Filis et al. (2011), and Ono (2011)). Recently, other studies have sought to determine if the relation between oil prices and stock returns is nonlinear. Performing a structural Vector Autoregressive (VAR) model specification, Wang et al. (2013) disentangled oil shocks into oil supply shocks and aggregate demand shocks. They examined their effects on stock market returns based on a sample comprising nine oil-importing countries and seven oil-exporting countries. The comparison of the magnitude, timing, and duration of the stock market's reaction to crude oil fluctuations indicates nonlinear and variant responses, depending on the net position of the country in the global market and driving forces of oil price shocks. In the same context, Le and Chang (2015) applied the approach of Toda and Yamamoto (1995) to explore if there is a nonlinear connection between hikes in oil prices and stock market returns. Not far from the results of Wang et al. (2013), the authors of this study found that the focal link varies conditionally on the oil characteristics and the nature of the shock in oil prices. This is also consistent with previous outcomes in the literature, showing that the impact of changes in oil prices potentially depends on the underlying cause of the change (Lippi and Nobili (2012) and Rapaport (2013)).

This study addresses the same questions but from several perspectives. First, following the studies of Wang et al. (2011) and Le and Chang (2015), it includes a longer observation period from 1998 to 2015 and employs a new econometric tool that accounts for frequency transformations. The focus of this study is to detect the effects of oil prices on the stock market returns of different investment horizons using a cyclical predictive approach. In this context, a causality measure in the frequency domain appears to be useful for gaining new insights into the structure of economic interactions in different frequencies (short-, medium-, and long-term). This distinction may help policymakers and practitioners in their decision making. In fact, it is possible to distinguish three possibilities. The first one is when a significant causality exists between oil and stock market returns in the components that slowly fluctuate (long-run causality). In this case, policymakers can take corrective actions a priori based on the information contained in oil prices. Another possibility concerns rapidly fluctuating components (short-run causality). In this case, it is inappropriate to take corrective initiatives since oil prices cannot properly and effectively determine the disturbances of stock prices. The third possibility is that there is no significant relation between the two considered variables. This means that oil prices have no predictive power for stock returns; thus, international 
investors cannot obtain accurate information about oil price fluctuations, and they cannot effectively react to risks.

Second, while it has been indicated in the large strand of literature that the nature of the country, oil intensity, and nature of oil shocks can considerably affect the interaction between oil prices and stock returns, this study specifically concentrates on the frequency relation between oil price and BRICS stock returns. Furthermore, this study determines whether there are other potential channels, in addition to the net global position of the country and its oil dependency, through which oil prices may differently and cyclically affect BRICS stock markets. This offers possible implications for international equity investors. To achieve this, a frequency domain causality test is applied. Heterogeneous outcomes have been shown among the BRICS countries. Based on the findings, they can be divided into three main groups of countries. The first one includes Brazil and Russia, where a causal relation between the stock returns and real oil price changes is supported in the long run. The second one includes only China, where the causality is well supported in the medium and long run. The third one includes India and South Africa, where a short-run causality exists. Several potential elements have been advanced to explain the mixed results among BRICS, including the stock market index concentration to oil, net position of the country in the global market, oil intensity of the GDP, concentration on oil-based revenues, dominance of cyclical sectors, oil efficiency, and governance.

The remainder of the paper is arranged as follows. Section II presents the principal model. Section III describes the data. Section IV reports and discusses the empirical results. Section V offers overall conclusions and some policy implications.

\section{Methodology}

The frequency domain causality test was employed in this study to help establish the relation between stock returns and real oil prices as well as to capture the dynamic relation among the economic variables of interest (under different frequencies). This technique comprises disentangling the slowly (low frequencies) and quickly fluctuating (high frequencies) components of a time series. More specifically, the Granger causality test can be assessed at different horizons. In this context, Geweke (1982) and Hsoya 
(1991) proposed measures for Granger causality under a frequency domain framework. Given their usefulness in various disciplines, testing frequency-by-frequency causality has been widely and extensively examined (Breitung and Candelon 2006). Interestingly, this technique, based on conditional data analysis, was used to examine if BRICS stock returns react differently to oil price movements, depending on cyclicality on the one hand and potential control variables (inflation, nominal exchange rate, industrial production, and real interest rate) ${ }^{1}$ on the other hand (Lee 1992). Overall, this test decomposes the link into three horizons: the short, medium, and long run.

Throughout this section, we briefly review the testing procedure proposed in Breitung and Candelon (2006). Let us, first, suppose that a two-dimentional time series vector $\left[x_{t}\right.$, $\left.y_{t}\right]$ is generated by the following stationary $\operatorname{VAR}(\mathrm{p})$ model:

$$
\left(\begin{array}{c}
x_{t} \\
y_{t}
\end{array}\right)=\left(\begin{array}{l}
\phi_{11}(L) \phi_{12}(L) \\
\phi_{21}(L) \phi_{22}(L)
\end{array}\right)\left(\begin{array}{c}
x_{t-1} \\
y_{t-1}
\end{array}\right)+\left(\begin{array}{l}
\mu_{t} \\
v_{t}
\end{array}\right)=\left(\begin{array}{l}
\psi_{11}(L) \psi_{12}(L) \\
\psi_{21}(L) \psi_{22}(L)
\end{array}\right)\left(\begin{array}{l}
\varepsilon_{t} \\
\eta_{t}
\end{array}\right), \mathrm{t}=1, \ldots, \mathrm{T}
$$

where $\phi_{i j}(L)=\phi_{i j, 1} L^{0}+\ldots+\phi_{i j, p} L^{p-1}$ for $i, j=1,2$ and $\left[\mu_{t}, v_{t}\right]^{\prime} \sim \operatorname{iid}\left(0, \sum\right)$. Note that is positive definite and let $\mathrm{G}$ be the lower triangular matrix of the Cholesky $G^{\prime} G=\sum^{-1}$; $\left[\varepsilon_{t}, \eta_{t}\right]^{\prime}$ is defined as $i, j=1,2$ and $\psi_{i j}(L)$ for $i, j=1,2$ are defined accordingly.

Then, the population spectrum of $x$, denoted by $f_{t}(\omega)$, can be derived from the previous matrix and expressed as follows:

$$
f_{x}(\omega)=\frac{1}{2 \pi}\left\{\left|\psi_{11}\left(e^{-i \omega}\right)\right|^{2}+\left|\psi_{12}\left(e^{-i \omega}\right)\right|^{2}\right\}
$$

The measure of causality proposed by Geweke (1982) and extended by Hosoya (1991) is represented as follows:

$$
M_{y \rightarrow x}(w)=\log \left[1+\frac{\left|\psi_{12}\left(e^{-i w}\right)\right|^{2}}{\left|\psi_{11}\left(e^{-i w}\right)\right|^{2}}\right]
$$

\footnotetext{
${ }^{1}$ The consideration of relevant stock market fundamentals that may have strong effect on the frequency causality between oil price and stock returns constitutes another contribution of this study. It is argued that by accounting for only two variables, the problem of simple regression without potential control variable emerges, which may distort the estimate and prevent use from properly capturing the link between the macroeconomic time series. For more details regarding the frequency domain causality-based conditional data analysis, please refer to Bouoiyour et al. (2015a).
} 
As $\left|\psi_{12}\left(e^{-i w}\right)\right|^{2}$ seems to be a complex function of the VAR parameters. Breitung and Candelon (2006), to resolve this drawback, argued that the hypothesis $M_{y \rightarrow x}(\omega)=0$ corresponds to a linear restriction on the VAR coefficients.

$$
H_{0}: R(\omega) \phi(L)=0
$$

where $R(\omega)=\left[\begin{array}{l}\cos (\omega) \cos (2 \omega) \ldots \cos (p \omega) \\ \sin (\omega) \sin (2 \omega) \ldots \sin (p \omega)\end{array}\right]$

The significance of the causal relation can be tested using a standard F-test or by comparing the causality measure for $\omega \in[0, \pi]$ with the critical value of a $x^{2}$ distribution with 2 degrees of freedom, which is 5.99 .

\section{Data}

To test the causal relation between oil price changes and stocks returns, this study utilizes data from quarterly observations from 1998 Q1 to 2015 Q2, where 70 observations are made in every time series. The sample is a representative from BRICS, which are distinct in terms of oil characteristics. Following Lee (1992), we consider five variables, i.e., Real Stock Returns (STR), Real Oil Prices (Oil), Industrial Production (IP), Nominal Exchange Rates (NEER), Inflation Rates (INF), and Real Interest Rates (IR). For the period ranging from 1998 Q1 to 2015 Q2, the following stock returns indexes are used: IBOVESPA $^{2}$ for Brazil, RTS ${ }^{3}$ Index for Russia, BSE Sensex $30^{4}$ Share Price Index for India, Shanghai Price Index for China, and $\mathrm{JSE}^{5}$ for South Africa (this data is obtained from the Quandl website). The real oil prices (available at the Energy Information Administration (EIA)) are denominated in each country's currency and deflated by

\footnotetext{
${ }^{2}$ IBOVESPA (or the Index of Bolsa de Valores de São Paulo) is a stock exchange located at São Paulo in Brazil.

${ }^{3}$ RTS stock market Index is cap-weighted composite index calculated based on the prices of the 50 most liquid Russian stocks of the biggest and dynamically developing Russian issuers presented on the Moscow Exchange.

${ }^{4}$ The BSE SENSEX 30 (Bombay Stock Exchange Sensitive Index) is a free-float market-weighted stock market index of 30 of financially sound companies. The 30 component companies seem the most actively traded stocks in India, and are representative of different industrial sectors.

${ }^{5}$ JSE (or the Johannesburg Stock Exchange) is the largest stock exchange in Africa.
} 
the consumer price index of each country. The remaining data related to Industrial Production (IP), Nominal Exchange Rates (NEER), Inflation Rates (INF), and Real Interest Rates (IR) are derived from Econstats ${ }^{\mathrm{TM}}$. The research period is motivated by the availability of the Brazilian and Chinese data and the fact that a common sample period is required for all of the investigated countries. In addition, this study transforms all of the considered variables by taking natural logarithms and correcting for potential heteroskedasticity and dimensional differences between the series. Then, we firstdifference the time series to generate a quarter-on-quarter time series and standardize them to exhibit a zero mean and variance of one. The descriptive statistics outcomes are reported in Table 1, except for Brazil, by log levels. The sample means of stocks returns and real oil price are positive for all of the countries studied. The skewness of real oil price appears to be negative (except for Russia), whereas that of stock returns is negative and positive among the countries studied, which is distinct in the consideration of oil. The kurtosis related to oil price is less important than three, except for Brazil, thus implying that the distribution is less flattened than the Gaussian distribution. Conversely, for stock returns, the kurtosis is above three for all of the cases. 
Table 1. Descriptive statistics

\begin{tabular}{|c|c|c|c|c|c|c|}
\hline & STR & Oil & IP & NEER & INF & IR \\
\hline \multicolumn{7}{|c|}{ Brazil } \\
\hline Mean & 0.05 & 2.45 & 4.44 & 4.51 & 2.59 & 2.58 \\
\hline Median & 0.03 & 2.56 & 4.42 & 4.550 & 3.69 & 2.32 \\
\hline Maximum & 0.90 & 4.14 & 4.74 & 4.81 & 5.50 & 4.17 \\
\hline Minimum & -0.91 & 0.74 & 4.18 & 4.20 & -7.90 & 1.94 \\
\hline Standard deviation & 0.33 & 0.65 & 0.14 & 0.14 & 3.22 & 0.57 \\
\hline Skewness & -2.22 & -0.80 & 0.17 & -0.49 & -1.95 & 1.20 \\
\hline Kurtosis & 9.56 & 3.91 & 2.33 & 2.70 & 5.72 & 3.53 \\
\hline Jarque-Bera & 15.63 & 9.91 & 1.62 & 3.06 & 10.34 & 17.59 \\
\hline \multicolumn{7}{|c|}{ Russia } \\
\hline Mean & 0.04 & 2.56 & 4.68 & 4.93 & 3.27 & 2.03 \\
\hline Median & 0.03 & 2.56 & 4.59 & 4.64 & 3.98 & 1.86 \\
\hline Maximum & 1.65 & 4.39 & 5.13 & 6.35 & 5.02 & 4.24 \\
\hline Minimum & -0.29 & 1.28 & 4.44 & 4.44 & -2.73 & 1.21 \\
\hline Standard deviation & 0.54 & 0.55 & 0.19 & 0.54 & 1.85 & 0.73 \\
\hline Skewness & 0.23 & 0.48 & 1.13 & 1.18 & -1.63 & 1.57 \\
\hline Kurtosis & 3.97 & 2.31 & 2.95 & 2.72 & 5.13 & 4.81 \\
\hline Jarque-Bera & 3.37 & 7.71 & 14.86 & 16.45 & 43.82 & 37.90 \\
\hline \multicolumn{7}{|c|}{ India } \\
\hline Mean & 0.00 & 4.21 & 4.25 & 4.45 & 4.30 & 2.59 \\
\hline Median & 0.00 & 4.28 & 4.27 & 4.47 & 4.39 & 2.56 \\
\hline Maximum & 0.55 & 5.10 & 4.88 & 5.23 & 4.78 & 2.99 \\
\hline Minimum & -0.59 & 3.22 & 3.67 & 3.85 & 3.64 & 2.37 \\
\hline Standard deviation & 0.18 & 0.41 & 0.33 & 0.28 & 0.31 & 0.17 \\
\hline Skewness & -0.10 & -0.15 & 0.00 & 0.54 & -0.44 & 0.62 \\
\hline Kurtosis & 5.15 & 2.08 & 2.06 & 3.82 & 2.02 & 2.43 \\
\hline Jarque-Bera & 13.52 & 2.72 & 2.53 & 5.29 & 5.04 & 5.33 \\
\hline \multicolumn{7}{|c|}{ China } \\
\hline Mean & 0.04 & 2.93 & 2.66 & 4.66 & 5.60 & 1.98 \\
\hline Median & 0.02 & 2.87 & 2.70 & 4.65 & 5.73 & 1.88 \\
\hline Maximum & 0.99 & 3.75 & 3.31 & 5.01 & 6.31 & 2.48 \\
\hline Minimum & -0.32 & 1.94 & 2.05 & 4.44 & 3.43 & 1.66 \\
\hline
\end{tabular}




\begin{tabular}{|l|l|c|c|c|c|c|}
\hline & STR & Oil & IP & NEER & INF & IR \\
\hline Standard deviation & 0.20 & 0.43 & 0.29 & 0.14 & 0.54 & 0.28 \\
\hline Skewness & 1.61 & -0.12 & 0.06 & 0.85 & -1.81 & 0.38 \\
\hline Kurtosis & 8.50 & 2.37 & 2.61 & 3.24 & 4.06 & 1.62 \\
\hline Jarque-Bera & 11.72 & 1.31 & 0.46 & 8.53 & 8.52 & 7.15 \\
\hline \multicolumn{7}{|c|}{ South Africa } \\
\\
\hline Mean & 0.01 & 4.17 & 4.47 & 4.79 & 4.34 & 2.49 \\
\hline Median & -0.00 & 4.27 & 4.47 & 4.72 & 4.33 & 2.51 \\
\hline Maximum & 0.31 & 5.05 & 4.69 & 5.29 & 4.97 & 3.08 \\
\hline Minimum & -0.28 & 3.16 & 4.24 & 4.23 & 3.73 & 1.94 \\
\hline Standard deviation & 0.08 & 0.42 & 0.11 & 0.31 & 0.33 & 0.29 \\
\hline Skewness & 0.24 & -0.22 & -0.04 & 0.14 & -0.03 & -0.36 \\
\hline Kurtosis & 5.32 & 2.04 & 2.15 & 1.73 & 1.97 & 2.28 \\
\hline Jarque-Bera & 16.16 & 3.27 & 2.07 & 4.81 & 3.03 & 2.98 \\
\hline
\end{tabular}

(Note) STR: Real Stock Returns; Oil: Real Oil Prices; IP: Industrial Production; NEER: Nominal Exchange Rates; INF: Inflation Rates; IR: Real Interest Rates.

\section{Results}

\section{A. Main findings}

The results of this study are suggestive of sharp variations in the causality pattern, which are not congruent with previous studies on the focal issue. Considering the relevant control variables, this study analyzes the predictive power of oil prices on the performance of the stock markets for from the 1998 Q1 to 2015 Q2 period. The results for each respective BRICS country are summarized as follows.

Figure 1 presents the test statistics with their 5\% critical values (dashed line) over the interval $[0, \pi]$. We evaluate if the real oil price Granger-cause real stock returns among the distinct frequencies involved. According to the results, three main groups can be considered. The first one includes Brazil and Russia, where a causal relation between the stock returns and real oil price changes is supported in the long run. The second one 
includes China, where the causality is well supported in the medium and long run. The third one includes India and South Africa, where a short-run causality exists. For Brazil, the null hypothesis of oil price, does not Granger-cause real stock returns, was rejected when $\omega \in[0.33 ; 0.87]^{6}$ (see Figure 1.A). This implies that the low frequencies of oil prices (with wave lengths of more than 7.2 quarters and less than 18.8) are able to offer predictive power for the stock markets. In Russia, a significant causality exists from real oil price changes to real stock returns in the lowest frequency bands (long run). The null hypothesis is verified for $\omega$ moving between 0.01 and 1.20 (more than 5.8 quarters). For India, the real oil price Granger-cause stock returns for $\omega$ less than 2.60 (less than 2.4 quarters, see Figure 1.C). The experience of China appears to be sharply different, especially since the causality was found to be at a wider cycle that fluctuates between 0.01 and 1.30 (medium- and long-term, see Figure 1.D). Meanwhile, South Africa's stock market appears to be less influenced by changes in oil prices, and thus, it is more resilient to oil price shocks. More specifically, a short-run causal link running from oil prices to stock market returns was found in the case of South Africa in which $\omega$ appears to be between 2.70 and 3.03 (less than 2.3 quarters, see Figure 1.E).

Recall that the frequency $(\omega)$ on the horizontal axis can be translated into a cycle or periodicity of $T$ quarters by $\mathrm{T}=(2 \pi / \omega)$, where $T$ is the period. 
Figure 1. The frequency domain causality between oil price and real stock returns

\section{A. Brazil}

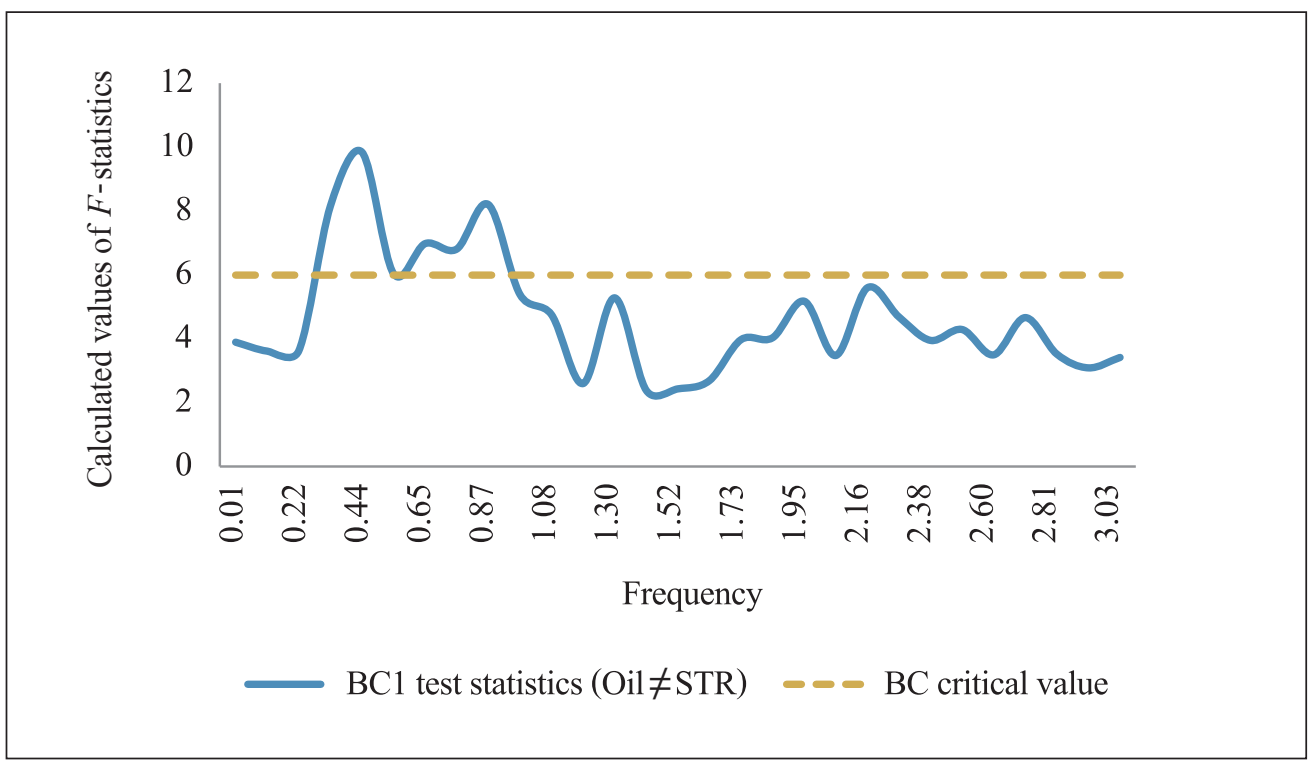

\section{B. Russia}

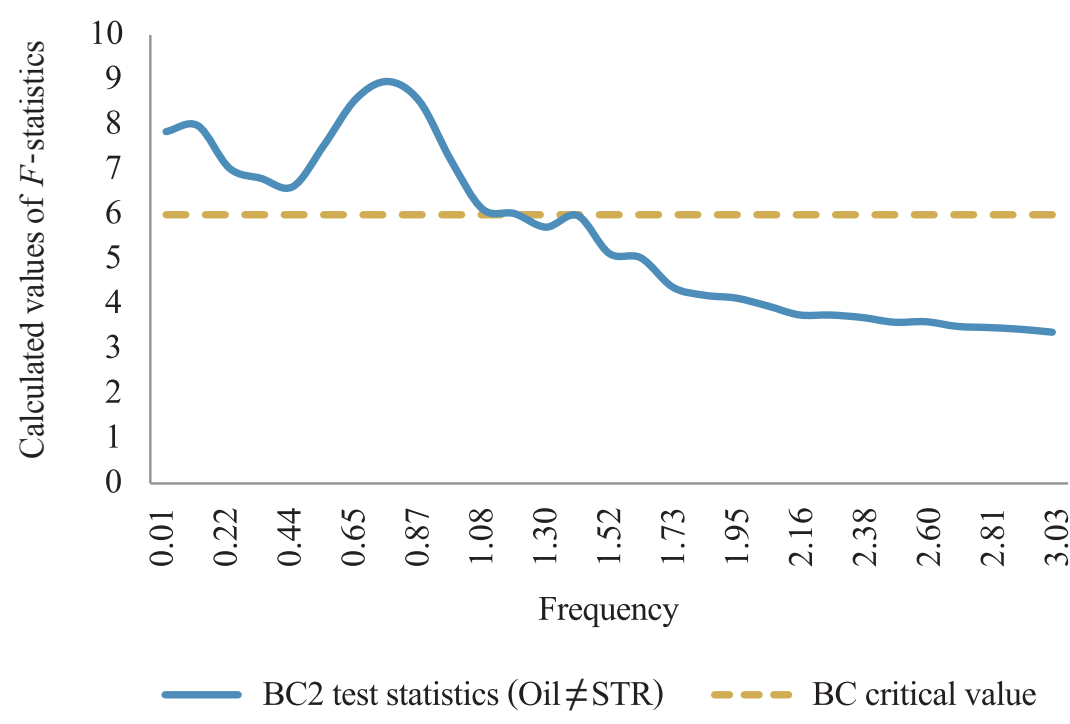




\section{India}



Frequency

$\mathrm{BC} 3$ test statistics $(\mathrm{Oil} \neq \mathrm{STR})-\infty \mathrm{BC}$ critical value

\section{China}

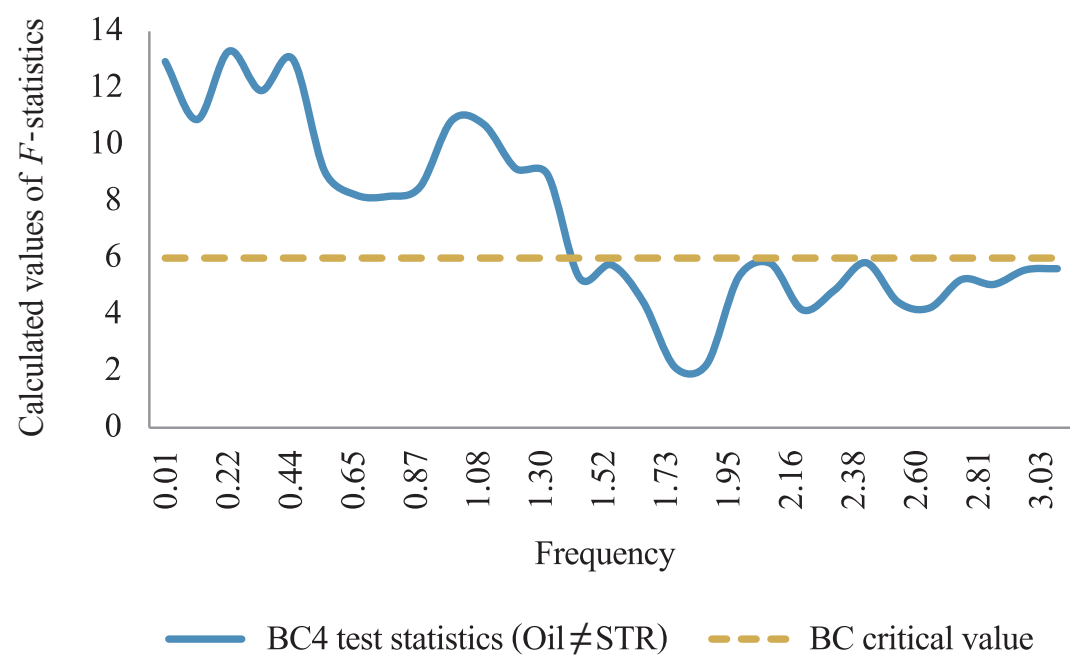




\section{E. South Africa}



Frequency

BC5 test statistics $(\mathrm{Oil} \neq \mathrm{STR}) \quad-\infty \mathrm{BC}$ critical value

(Note) BC:Breitung and Candelon's test (2006), Oil:Real Oil Price Changes, STR:Stock Returns.

\section{B. Interpretations}

With regard to interpretations, let us begin with the case of Brazil. Bovespa is the major stock exchange in Brazil, with a market capitalization (million US dollars) of $\$ 1,229$ in 2014. This stock market index has received significant attention by international investors in recent years. Energy and basic materials constitute $50.29 \%$ of the Bovespa (see Appendix 1), while Petrobras is responsible for a large amount of the volume traded in the Brazil's equity returns. In fact, there are highly indexweighted companies, such as Vale and Petrobras (with approximately $17 \%$ of market capitalization of the index), highlighting that Bovespa is highly sensitive to excessive oil price fluctuations (Bouoiyour et al. 2015a). Since 2011, Brazil has been an oil-exporting country. However, the country is still an importer of some light oil (the dependency on oil imports amounts to $10.2 \%$ ). In addition, oil intensity of the Gross Domestic Product (GDP) appears to be considerable (11\%, see Appendix 2). It is in this regard that a long-run causal relation was found between real oil price and stock returns. Given the strong market concentration, financial underperformance of these companies may have 
a strong and detrimental impact on the Brazilian stock exchange (Bhar and Nikolova 2009). This implies that international investors should refer to these results as a guide in the hopes of gaining an advantage when investing in the Brazilian market. Despite the achievement of oil sufficiency since 2006 (The Office of Global Energy Dialogue (2006)), Brazil appears to be unable to avoid the detrimental effects of sudden oil shocks and manage the swelling volatility of crude oil. This may be based on the fact that the oil industry is fragile in terms of knowledge among the Brazilian research community (Oliveira and Rubiano 2012). This highlights the importance of enhancing Brazil's knowledge base through new paths and radical innovations. In addition, Petrobras should work to improve the network of equipment and service suppliers in the oil industry to avoid technological uncertainty. Furthermore, due to its relatively new position as an oil exporter, Brazil's government should carefully manage the sizable volatility of its exports and revenues brought about by the volatile behavior of oil prices. This can be achieved by adopting flexible exchange rates.

The findings also suggest that oil price movements may significantly destabilize Russian equity markets. This is because high oil dependency increases the susceptibility of the considered economy to excessive oil price fluctuations. In Russia, the oil intensity of the GDP appears to be the strongest among BRICS (34\%, see Appendix 2). Moreover, oil exports heavily determine government revenues and expenditures as well as aggregate demand. In this context, the impact of oil price volatility on demand will substantially affect inflation, thereby influencing discount rates and stock markets. Since 1993, the energy sector has been privatized, which coincided with the creation of the Moscow stock exchange market in 1994. Since its creation, the Russian stock market has been distinguished during the heavy dominance of companies that operate in the oil and gas industry (60.2\%). The Russian equity market became hyper concentrated in which the global energy company Gazprom ${ }^{7}$ represents $15.2 \%$ and hydrocarbons constitute approximately $45 \%$. This concentration may negatively impact the stock market due to the financial underperformance of Russian companies and other adverse events, as evidenced by the negative influence of the Yukos affair (Bhar and Nikolova 2009). According to these findings, international investors should be cautious about Russia's oil sector challenges, including the underdeveloped regulatory framework, low domestic prices, and the insufficient ability to deliver oil resources (coupled with infrastructure underdevelopment). Moreover, the export duties and taxes charged to major oil

Gazprom is a large Russian company founded in 1989. It carries on the business of extraction, production, transport and sales of natural gas. 
producers would obviously discourage export activities, decreasing domestic prices, and harm the development of new oil fields (Bhar and Nikolova 2010). Furthermore, the current geopolitical tension and the economic sanction, in particular the Crimean crisis, may disturb oil exports and expand oil price volatility in the future, thus bringing stock market uncertainty (Bouoiyour et al. 2015b). It must be pointed out in this context that geopolitical events may lead to a temporary drop in oil production, are usually unpredictable (Wang et al. 2013). Considering the above findings, it can be concluded that to build long-run international investors' confidence in the stock markets and avoid interrupted oil exports, the Russian authorities should implement a strategy that promotes the development of new oil fields and pipelines, increases domestic energy efficiency, and invests in an appropriate infrastructure network. Finally, an adjustment of fiscal budget by diversifying sources of revenue or by improving nonoil-based revenues seems highly warranted to ensure continued growth of the Moscow stock exchange. This can be appropriately achieved by reinvesting the money generated from oil into other assets that can be used to gain more revenues.

In the cases of India and South Africa, we have shown that oil prices are the leading indicators for stock market performance in the short run. For the first country, while the stock market is characterized by a wider concentration among several companies and sectors, gas and oil production companies represent only $1.4 \%$ of the exchange market. Sectoral concentration is evident from the fact that out of the top 50 companies, those in the Information Technology sector constituted as much as $67 \%$ of the market turnover (IIFL 2015). In South Africa, the performance of the JSE has been robust, albeit volatile, with a large concentration on the banking sector (56\%), while oil and gas companies represent a low percentage $(4 \%)$ of the total stock market capitalization (see Appendix 1). While the dependency on oil imports seems to be important for both India and South Africa (25.6\% and 20\%, respectively, see Appendix 2), the positions of these countries in terms of the regulation of securities exchanges and financial system efficiency have played a powerful role in mitigating oil price volatility. In South Africa, the achievement of a fast-track listing process has helped international investors avoid the detrimental effects of the volatile behavior of oil prices (Ferhani and Sayeh 2008). According to the World Economic Forum's Global Competitiveness Survey (2015), South Africa has been ranked 1st out of 144 emerging countries with regard to its ability to raise finance via the local equity market (Bouoiyour et al. 2015c). For India, the central government is also actively involved in regulating the stock markets to safeguard the confidence of international investors (Campbell 2009). 
In 2012, China represented 43\% of the world's oil demand (EIA 2012). In addition, China's oil intensity amounts to $23 \%$, while its dependency on oil imports constitutes more than 32\% (see Appendix 2). Due to its high growth rate of oil demand and its wider consumption, the impact of oil price changes generated by precautionary demand shocks on Chinese equity returns is expected to be strong. The inefficiency of the Chinese stock market may be perceived to be responsible for the immediate transmission of information from the crude oil market to the stock market, thus leading to negative consequences related to oil shocks (Groenewold et al. 2004, Wang et al. 2013). To avoid a possible dark scenario, lessening oil dependency through the use of oil substitutes, coupled with effective regulation of the financial markets, may help China become more flexible in reacting to any future increases in oil prices and mitigating oil imports expenditures. Furthermore, the Chinese stock market is mainly characterized by its volatility. No less than 50 periods of ups and downs have occurred since 1990 (Bouoiyour et al. 2015c), which is a specific characteristic of this stock market. It is in this case where this study shows a significant medium-and long-run influence of oil price changes on stock returns. The concentration of listed companies by sector and size contribute widely to stock market volatility. Moreover, the sectoral distribution of the Shanghai index, which appears to be highly concentrated on cyclical sectors, can increase the volatility of the Chinese exchange market. Furthermore, the weight of cyclical sectors is estimated to be approximately $84 \%$ for raw materials, while that of energy amounts to $15.9 \%$ (see Appendix 1). Indeed, this market is sharply distinguished by a skewed distribution of cyclical and noncyclical sectors (Miao and Peng 2007). It must be added that there is an unbalanced sectoral distribution not only for China but also for all the BRICS stock markets, with sharp dominance of cyclical sectors. Therefore, a balanced mix of sector representation in the stock market is recommended to overcome the possible negative consequences of oil price volatility on the performance of the Shanghai Composite Index in particular and the BRICS stock market indexes in general.

In sum, the results of this study are intuitive in two ways. First, the short-run causality running from real oil price to stock returns is supported for countries that have tightened their regulation of the stock markets. India and South Africa offer secure and efficient capital markets through a diverse range of instruments, such as cost-effective services, thus making their stock markets attractive listing destinations. Second, the long-run causal relation between real oil price and stock returns is sharply depicted among three countries (Brazil, Russia, and China). While the shares of oil sectors in the stock market exceed $50 \%$ and $60 \%$ for Brazil and Russia, respectively, it only amounts to $15.9 \%$ (less 
than the half) for China. Likewise, different outcomes have been found in terms of the dependence on oil imports, which appears to be stronger for China (33\%) compared with Brazil (10.2\%) and Russia (see Appendix 2). This highlights the existence of other channels through which oil may affect stock returns differently, including the heavy concentration on oil-based revenues and regulatory securities exchanges.

To ensure the robustness of the results, the underlying connection between BRICS stock returns and oil prices was reinvestigated by making some changes in the control variables (i.e., by replacing the industrial production by the GDP). ${ }^{8}$ The results remain fairly stable. Indeed, this study unambiguously shows that BRICS may be decomposed into three main groups: 1) short-run causality from Oil to STR, as depicted in India and South Africa; 2) medium- and long-run linkage, as seen in the case of China; and 3) long-term causality, as seen in Brazil and Russia. Therefore, it is confirmed that when supporting a long-run causal relation, it is difficult to tackle all of the channels through which real oil price cyclically affects BRICS equity returns. In addition to the nature of the country and oil dependency, other potential factors, such as the lack of diversification in terms of oil-based revenues, should be accounted for.

\section{Conclusions}

This study compared the frequency causality between oil price changes and real stock returns among BRICS countries from 1998 Q1 to2015 Q2. This remains an important topic that needs to be reanalyzed, especially since these countries are expected to consume a substantial share of the world's oil supply and become larger players in the global financial market.

Testing for Granger causality in the frequency domain, the sample can be divided into heterogeneous subgroups. The first one includes Brazil and Russia, where causality running from oil prices to real stock returns is supported in lower frequencies (long run). The second one includes China, where a significant causality exists in quite a large cycle (medium and long run). The third subgroup includes India and South Africa, where a short-run causality is supported. This study improves upon the existing literature by

\footnotetext{
${ }^{8}$ To keep this presentation as simple as possible, the detailed findings are available upon request.
} 
identifying further potential factors that may have an influential role on the Real Oil Price (Oil)-Real Stock Returns (STR) nexus. In addition to the net position of the country and oil dependency, which were largely advanced in previous studies to explain the different responses of stock markets to oil prices, supplementary channels through which Oil may differently and nonlinearly affect real stock returns have been added in this research. These channels include the extreme concentration on oil-based revenues and the skewed distribution of cyclical and noncyclical sectors.

Beyond the nuances of short-, medium- and long-run causality, being cautious about the significant influence of oil price changes on BRICS stock markets appears to be crucial for regulators when discerning the causality horizons, safeguarding the BRICS stock markets from uncertainty, and reacting to the volatility of the world's oil market. More importantly, a more effective stock market depends on four overall factors: 1) improving oil efficiency and improving knowledge bases within Brazil's research framework; 2) mitigating taxes charged to major oil-producing companies and reinvesting the money generated from oil into other assets that can be used to generate further revenues in Russia; 3) minimizing the higher dependence on cyclical sectors for all of the BRICS countries in general and for China in particular; and 4) actively regulating market securities to ultimately safeguard the efficiency of the financial system.

Intuitively, cognizant of the significant relation between the BRICS stock markets and oil prices conditioning upon Industrial Production (IP), Real Interest Rates (IR), Nominal Exchange Rates (NEER), and Inflation Rates (INF), appropriate policy measures are warranted. First, the impact of oil price on BRICS stock markets depends on adopting industrial production and promoting measures that can enhance the capital market. Second, pursuing suitable monetary policy measures and carefully guiding interest rates are also necessary for mitigating inflationary pressures and preserving the purchasing power of money, respectively.

Finally, the findings of this study are useful for regulators and investors. Regulators should be cautious of the effect of oil price fluctuations on BRICS stock markets. Thus, it is important to build long-run international investors' confidence in the stock markets. This can be done by protecting and safeguarding their interests against risk and uncertainty stemming from the oil market and by reducing their stock market's oil dependency. For the investors, it is important to properly predict the performance of stock markets by examining the frequency linkage between oil prices and real stock returns. 
Received 5 November 2015, Revised 22 June 2016, Accepted 9 July 2016

\section{References}

Al Janabi, M.A.M., Hatemi, J.A., and Irandoust, M., "An empirical investigation of the informational efficiency of the GCC equity markets: evidence from bootstrap simulation," International Review of Financial Analysis 19 (2010): 47-54.

Apergis, N. and Miller, S. M., "Do Structural Oil-market Shocks Affect Stock Prices?" Energy Economics 31 (2009): 569-75.

Bhar, B. and Nikolova, B., "Oil Prices and Equity Returns in the BRIC Countries", World Economy 32 (2009): 1036-54.

Bhar, B. and Nikolova, B., "Global oil prices, oil industry and equity returns: Russian experience", Scottish Journal of Political Economy 57(2010): 169-86.

Bouoiyour,J., Selmi, R., Tiwari, A-K. and Shahbacz, M., "The Nexus between Oil price and Russia's Real Exchange rate: Better Paths via Unconditional vs Conditional Analysis", Energy Economics 51 (2015 a): 54-66.

Bouoiyour, J., Selmi, R. and Tiwari, A-K., "The Co-movement and causality between Inflation and Russia's Stock Market: New Light via Time-Frequency approaches", Working paper, CATT, University of Pau (2015 b).

Bouoiyour, J., Selmi, R. and Miftah, A., "How can stock return predict industrial production in BRICS? A comparative analysis through frequency causality", Working paper, CATT, University of Pau (2015 c).

Breitung, J., and Candelon, B. 2006, "Testing for short and long-run causality: a frequency domain approach", Journal of Econometrics 132 (2006): 363-78.

Cologni, A., and Manera, M., "Oil Prices, Inflation and Interest Rates in a Structural Cointegrated VAR Model for the G-7 Countries", Energy Economics 30 (2008): 856-88.

Ferhani, H-J., and Sayeh, A-M., "South Africa: Financial System Stability Assessment, Including Report on the Observance of Standards and Codes on the following topic: Securities Regulation", IMF country report n 08/349 (2008). 
Filis, G., Degiannakis, S. and Floros, C., "Dynamic correlation between stock market and oil prices: the case of oil-importing and oil-exporting countries", International Review of Financial Analysis 20 (2011): 152-64.

Geweke, J., "Measurement of linear dependence and feedback between multiple time series", Journal of American Statistical Association 77 (1982): 304-24.

Groenewold, N., Tang, H.K. and Wu, Y., "The dynamic interrelationships between the Greater China share markets", China Economic Review 15 (2004): 45-62.

Huang, R., Masulis, R.W. and Stoll, H.R., "Energy Shocks and Financial Markets", Journal of Futures Markets, 16 (1996): 1-27.

Jones, C.M., and Kaul, G., "Oil and the Stock Market", Journal of Finance 51 (1996): 463-91.

Kilian, L., and Park, C., "The impact of oil price shocks on the US stock market", International Economic Review 50 (2009): 1267-87.

Le, T-H., and Chang, Y., "Effects of oil price shocks on the stock market performance: Do nature of shocks and economies matter?" Energy Economics 51 (2015): 261-74.

Lee, B-S., "Causal relations among stock returns, interest rates, real activity and inflation", Journal of Finance 47 (1992): 1591-604.

Lippi, F., and Nobili, A., 2012, "Oil and the macroeconomy: a quantitative structural analysis", J. Eur. Econ. Assoc. 10 (2012): 1059-83.

Maghyereh, A. "Oil price shocks and Emerging stock markets: A generalized VAR Approach", International Journal of Applied Econometrics and Quantitative Studies 1 (2004).

Narayan, P.K. and Narayan, S., "Modelling the impact of oil prices on Vietnam's stock prices," Applied Energy 87 (2010): 356-61.

Oliveira, A., and Rubiano, D., "Innovation in Brazilian Oil Industry", Universidade Federal de Rio de Janeiro (2012).

Ono, S., "Oil Price Shocks and Stock Markets in BRICs," The European Journal of Comparative Economics 8 (2011): 29-45.

Park J., and Ratti R.A., 2008, "Oil Price Shocks and Stock Markets in the U.S. and 13 
European Countries”, Energy Economics 30 (2008): 2587-608.

Rapaport, A., "Supply and demand shocks in the oil market and economy-wide shocks that affect asset prices." Chicago Booth Research Paper (2013).

Papapetrou, E., “Oil Price Shocks, Stock Market, Economic Activity and Employment in Greece", Energy Economics 23 (2001): 511-32.

Sadorsky, P., "Oil price shocks and stock market activity”, Energy Economics 21(1999): 449-69.

Shimon, A., and Raphael, S., "Exploiting the Oil-GDP effect to support renewable development", Energy Policy 34 (2006): 2805-19.

Toda, H.Y. and Yamamoto, T., "Statistical inference in vector autoregressions with possibly integrated processes", Journal of Econometrics 66 (1995): 225-50.

Wang, Y., Wu, C. and Yang, L., 2013, "Oil price shocks and stock market activities: Evidence from oil-importing and oil-exporting countries", Journal of Comparative Economics 41 (2013): 1220-39. 
Appendix 1: Sectoral distribution of the stock market index

$(\%)$

\begin{tabular}{|l|c|c|c|c|c|}
\hline \multicolumn{7}{|c|}{ Sectors } & Brazil & Russia & India & China & $\begin{array}{c}\text { South } \\
\text { Africa }\end{array}$ \\
\hline \multicolumn{7}{|c|}{ Cyclical sectors } \\
\hline Oil and raw materials & 50.2 & 60.2 & 1.4 & 15.9 & 4.0 \\
\hline Financials and Banks & 21.9 & 9.7 & 2.6 & 31.7 & 56.0 \\
\hline Industrial and manufacturing & 6.3 & 6.1 & 9.1 & 31.9 & 8.3 \\
\hline Information technology & - & 3.2 & 67.0 & 4.4 & 2.9 \\
\hline Total & 78.4 & 79.2 & 80.1 & 83.9 & 71.2 \\
\hline Non-cyclical sectors & & & \\
\hline Consumer goods & 9.5 & 11.2 & 6.8 & 6.4 & 9.8 \\
\hline Telecommunications & 4.3 & 4.1 & 10.4 & 1.2 & 7.0 \\
\hline Others & 7.8 & 6.4 & 2.7 & 8.5 & 11.8 \\
\hline \multicolumn{1}{|c|}{ Total } & 21.6 & 20.8 & 19.9 & 16.1 & 29.8 \\
\hline
\end{tabular}

(Source) CME group, Bloomberg India-infoline (IIFL) websites.

\section{Appendix 2: Oil characteristics among BRICS}

\begin{tabular}{|c|c|c|}
\hline & Oil intensity & Dependence on oil imports \\
\hline Brazil & 11.0 & 10.2 \\
\hline Russia & 34.0 & - \\
\hline India & 14.0 & 25.6 \\
\hline China & 23.0 & 32.8 \\
\hline South-Africa & 27.0 & 20.0 \\
\hline
\end{tabular}

(Note) Oil intensity is calculated as units of energy per unit of GDP. The dependence on oil imports is equal, based on the Energy Monthly Review, to (the net inflow of oil/products supplied)*100.

(Source) CME group, Bloomberg, India-infoline (IIFL) and OEC-atlas websites. 